American Journal of Pharmaceutical Education 2020; 84 (7) Article 7695.

\title{
RESEARCH
}

\section{Study Behaviors Associated with Student Pharmacists' Academic Success in an Active Classroom Pharmacy Curriculum}

\author{
Kimberly C. McKeirnan, PharmD, ${ }^{a}$ Karen Colorafi, PhD, MBA, ${ }^{\mathrm{b}}$ Anne P. Kim, PharmD, MPH, \\ Angela S. Stewart, PharmD, ${ }^{c}$ Connie M. Remsberg, PharmD, PhD, ${ }^{a}$ Myphuong Vu, \\ Brenda S. Bray, MPH, BPharm ${ }^{\mathrm{a}}$ \\ ${ }^{a}$ Washington State University College of Pharmacy and Pharmaceutical Sciences, Spokane, Washington \\ ${ }^{\mathrm{b}}$ Gonzaga University, School of Nursing and Human Physiology, Spokane, Washington \\ ${ }^{c}$ Washington State University College of Pharmacy and Pharmaceutical Sciences, Yakima, Washington \\ Submitted May 23, 2019; accepted November 22, 2019; published July 2020.
}

\begin{abstract}
Objective. To identify the specific study behaviors that promoted student pharmacists' success in an active-learning pharmacy curriculum.

Methods. The Washington State University College of Pharmacy and Pharmaceutical Sciences implemented an active-learning, flipped classroom model for instruction to equitably deliver course content to Doctor of Pharmacy students on both its main and extended campuses. Students' ability to adapt to the new model and its impact on their study behaviors were unknown. A qualitative descriptive design that included semi-structured interviews was applied to evaluate the study behaviors of high-performing students. The study sample included 13 third and fourth professional year pharmacy students in the top $20 \%$ of their respective classes.

Results. Interview responses were unaffected by baseline demographics such as gender and year of graduation. Content analysis generated five primary themes related to the behavioral strategies used by high performers: preparing for class, preparing for testing, seeking help, knowing yourself, and building on strengths. These were mapped to the four tenants of Wenger's social learning theory in the representation of findings: learning as doing, learning as belonging, learning as becoming, and learning as experience.

Conclusion. High-performing students demonstrated a refined ability to select and modify study behaviors that aided in their academic success, demonstrating a high degree of metacognition. The results of this research may assist pharmacy faculty members in identifying critical elements for success of students enrolled in pharmacy programs using an active learning model.
\end{abstract}

Keywords: student study habits, active learning, qualitative interview

\section{INTRODUCTION}

Understanding what differentiates academically high-performing students from low-performing students has been the focus of numerous educational research studies. Research into the characteristics of students who achieve academic success revolves around self-regulated learning: the idea that successful students are better able to understand concepts when they self-direct their learning environment. ${ }^{1}$ Decades of research on self-regulated learning suggest it is a cycle of three phases: forethought,

Corresponding Author: Kimberly C. McKeirnan, Washington State University College of Pharmacy and Pharmaceutical Sciences, 412 E. Spokane Falls Blvd., Spokane, WA 99210. Tel: 509-358-7722. Email:

kimberly.mckeirnan@wsu.edu performance, and self-reflection. ${ }^{2}$ Academically highperforming students routinely engage in effective, selfregulated learning. ${ }^{3}$

Self-regulated learning involves components such as motivation, metacognition, help-seeking behaviors, and time management and study strategies. ${ }^{1,4}$ Studies have shown a positive relationship between student motivation and academic achievement. Students with high selfefficacy (ie, the belief they are capable of learning the material) and students who place high intrinsic value on learning the content are more likely to have stronger academic performance. ${ }^{4}$ The link between students' metacognition (ie, awareness of their own knowledge) and their academic performance has also been demonstrated. Schneider and colleagues found that high-performing pharmacy students used superior metacognitive skills in 


\section{American Journal of Pharmaceutical Education 2020; 84 (7) Article 7695.}

identifying their level of performance on summative examinations compared with low-performing students. ${ }^{5}$ Further research demonstrated that pharmacy students with greater academic competence, or perceived confidence in their academic abilities, were more likely to seek out help from faculty members. ${ }^{6}$

In addition to individual student learning characteristics and motivation, studies report a variety of student study behaviors that may contribute to academic success. ${ }^{7-10}$ Academically successful students tend to manage their time more efficiently and use more effective study strategies than their less-successful peers. These strategies include distributing learning over time, interweaving study topics, and practice testing. ${ }^{7,11}$ Time management, including the prioritizing, planning, and scheduling of study time, is a critical skill for student success. ${ }^{11}$ Good time management ${ }^{8,9}$ and self-testing aids $^{8}$ were found to be strong predictors of first-semester academic performance among medical and nursing students. The most important factor in differentiating high- vs low-performing pharmacy students is testing competence: the ability of a student to manage the amount of material on any given assessment. Sansigry and colleagues ${ }^{10}$ determined that testing competence (the ability of a student to manage the amount of material on an assessment) was the most important factor in differentiating high- vs low-performing pharmacy students. Despite evidence of the importance of using effective study behaviors and strategies and their association with high academic performance, Persky found that pharmacy students tended to rely heavily on rereading or rewatching videos as a primary study strategy. ${ }^{12,13}$ Over time, the same students decreased their use of practice testing.

Much of the research conducted to date has focused on understanding student achievement in traditional classrooms. Few studies have attempted to identify what helps students achieve academic success in a classroom environment that relies heavily on active and collaborative learning strategies. One such study by Boeve and colleagues considered how students' study behaviors differed between a traditional classroom and a flipped classroom and how these behaviors related to student performance, but no clear differences in study behaviors were observed. ${ }^{14}$ When looking at the relationship between study behaviors and student performance, only practice testing or self-testing on the material for the flipped course was significantly correlated with better student performance. ${ }^{14}$

Washington State University College of Pharmacy and Pharmaceutical Sciences (WSU CPPS) uses an active-learning classroom approach program wide. ${ }^{15,16}$ The active-learning or "flipped" classroom model is intended to maximize students' learning experience and success in the pharmacy curriculum. Compared to the one-dimensional traditional classroom, a flipped classroom is considered a three-dimensional classroom because it involves learning interactions between professors and students, students and students, and students and their world. ${ }^{16}$ Therefore, the flipped classroom serves to provide students with more advanced stages of learning, increase interactions with professors and fellow students, promote active-learning strategies in and outside the classroom, and enhance retention of information long term. ${ }^{16}$

The goal of flipped classrooms is to encourage highlevel learning. In flipped classrooms, students' first exposure to lecture materials is prior to class. They are required to read pre-class material, watch or listen to video-recorded lectures, and/or complete pre-class assignments. ${ }^{17}$ This introduces students to material on their own time, at their own speed, in a manner that works best for them. In-class material is structured with guided-learning activities designed to provide students with higher levels of cognitive learning. Students collaboratively work on problem-solving, case studies, group discussions, projects, and games to develop necessary career skills. In-class activities require students to apply, analyze, and evaluate learned pre-class materials in case-based situations intended to develop professional skills such as effective communication and teamwork.

The WSU CPPS implemented the active-learning classroom model as a unique approach to education on extension campuses when its branch campus opened in 2015. The approach essentially "flipped" the entire curriculum on both the main campus (Spokane, WA) and the branch campus (Yakima, WA). Students on both campuses complete the same pre-class materials (ie, prerecorded videos, readings) and then attend class on their respective campuses to apply and synthesize knowledge from pre-class content. The specific active-learning activities that take place during class time vary by course but include strategies such as case studies, games, role playing, team-based learning, and others. A course instructor on the main campus is paired with a co-instructor on the branch campus to ensure a similar classroom experience for students in both locations. This active-learning classroom model encompasses all courses within the Doctor of Pharmacy program, including foundational science-based and therapeutics-focused courses. Prior to implementation, an extensive faculty development program provided course instructors with training opportunities and tools related to active-learning classroom management and teaching strategies. Faculty members and other instructors (including resident pharmacists and 


\section{American Journal of Pharmaceutical Education 2020; 84 (7) Article 7695.}

fellows) reported varying degrees of comfort with the active-learning model. Internal college surveys conducted during the initial years of implementation indicated that faculty members were confident in their ability to align pre-class and in-class activities, but were less confident in their ability to engage the entire class and to assess the effectiveness of in-class activities.

Many pharmacy programs have implemented activelearning strategies, including flipped learning, team-based learning, and problem-based learning. Considerable research on these active-learning pharmacy programs has focused on assessing student perceptions and performance. Several published reports have described best practices for effective teaching in active-learning classrooms. ${ }^{18-20}$ Despite these examples from the literature, there is a paucity of research to date regarding student success strategies in an active-learning classroom. This is interesting considering the emphasis that the Accreditation Council for Pharmacy Education (ACPE) places on colleges of pharmacy to use active-learning strategies throughout their curriculums. Research describing factors associated with pharmacy student academic success is urgently needed.

Wenger's social theory of learning was the theoretical framework used to guide this study. ${ }^{21,22}$ The theory is based on four foundational premises: learners are social beings, knowledge is a matter of competence, knowing is about active engagement, learning ultimately produces meaning. According to Wenger, learning is an act of social participation whereby individual students are called to engage in and contribute to the practice of their community, in this case, the community of students studying to become pharmacists. The framework of Wenger's social theory of learning requires organizations to support learning by sustaining its communities of practice, and notes that the way in which communities of practice refine learning is through the involvement of new members. In this refinement of the behaviors of learning, we sought to explore specific study behaviors that promoted student pharmacist success in an active-learning classroom setting. Our research objective was to determine what behaviors high-performing students engage in.

\section{METHODS}

For this study of behaviors that promoted student pharmacists' success in an active-learning pharmacy curriculum, a qualitative descriptive design was selected. ${ }^{23-25}$ This was appropriate as the research question related to a subject that required initial exploration (the success of students in an active-learning classroom) and a complex, detailed understanding of the issue. As in any qualitative study, the findings could be used to generate hypotheses for further testing. ${ }^{26}$ Semi-structured interviews were conducted to search for similarities, differences, and patterns among high-performing students enrolled in the school. Faculty members with expertise in active learning and student success created the interview questions using the theoretical model. Interview questions are displayed in Appendix 1. Topics that had previously been identified during course evaluations and a review of the literature describing factors related to active-classroom learning were incorporated. Questions were refined iteratively by the research team until each member was satisfied. The WSU Office of Research Assurances reviewed this protocol and found the project to be exempt from review by the Institutional Review Board.

In the university's competency-based assessment model, there is no traditional grade point average (GPA) calculation. Instead, a cumulative course average percentage is used to determine student class rank. Membership in the Rho Chi Honor Society is offered to students with a course average percentage in the top $20 \%$ of the class based on final course percentages after the third semester. For the purpose of this study, academic success was defined as initiation into the Rho Chi Honor Society and a course average percentage in the top $20 \%$ of their respective classes. Eighty-one of the 557 students in the classes of 2019 and 2020 met these criteria for inclusion in the study. All pharmacy students enrolled at the time of the study were exclusively exposed to an activelearning environment.

The 81 students eligible for inclusion were invited to participate in the study in an email sent by one of the investigators. Two weeks after the first email was sent, a follow-up email was sent to eligible students who had not responded. Fourteen students responded that they were interested in participating in the study and serving as a key informant. These students were asked to contact a member of the research team, who confirmed the student's email address and phone number. This faculty member also confirmed the students' permission for their contact information to be given to the research team member who would conduct the key informant interview, who was not a faculty member at CPPS.

The research team selected a non-CPPS faculty member to conduct the interviews because she had previous qualitative research experience and did not have prior knowledge of the study participants. Selecting an interviewer from outside CPPS was also intended to protect student privacy and to encourage honest responses. The interviewer contacted each student by email to arrange a time acceptable to the student to conduct the interview. Thirteen of the 14 students were interviewed over a six-week period. One student who initially 


\section{American Journal of Pharmaceutical Education 2020; 84 (7) Article 7695.}

expressed interest in participating in the study failed to respond to requests to schedule an interview. Interviews were conducted over the phone and took between 30 and 40 minutes to complete. Recruiting additional students to participate was planned in the event that saturation was not reached; however, this was deemed unnecessary at the conclusion of the interviews.

During the telephone interview, demographic information, including the student's age, gender, and graduation year were collected. Students were asked to state what undergraduate degrees they had earned before beginning pharmacy school and to indicate their previous exposure to active learning and to pharmacy practice (ie, pharmacy intern, assistant, technician, volunteer). Fiftyfour percent $(n=7)$ of the qualifying students attended classes on the main campus and $46 \%(n=6)$ attended classes at the branch campus. The 13 participants represented $2 \%$ of all students $(n=557)$ in the classes of 2019 and 2020 .

Student interviews were recorded and transcribed, and the resulting data were analyzed by the non-CPPS faculty interviewer in order to protect students from potential re-identification and avoid the possibility of unconscious bias in future assessments by CPPS faculty members. Any identifying information was redacted before the transcripts were used for analytic memoing and coding. Memoing is the process of writing reflective notes about what is observed in the data which the researcher can later use in data analysis. ${ }^{27}$ Coding procedures outlined by Miles, Huberman, and Saldana were used to perform first-level coding by hand. ${ }^{25,27}$ First-level coding, a systematic method for labeling things that appear repeatedly in the text, was then clustered into higher-level categories that represented student behavior. Multiple data matrices were created to understand the relationships between variables and to categorize and understand student responses. At the point of second-level coding, where clustered categories could be presented and the voices of the participants were therefore intertwined and de-identified, other members of the research team were included in the analysis. In keeping with the qualitative tradition of providing an "audit trail," an example of our first- and second-level coding is provided in Table 1. The codes and categories were discussed at length. Students were asked to perform member checking and their feedback (restricted to minor details about facts and dates) was incorporated. Once inter-rater agreement of the categories was reached through discussion and consensus, the qualitative software program Dedoose (Stanford, CA) was used to upload transcripts and identify and file meaning units under the final, agreed upon categories. ${ }^{27}$ Further discussion by the research team at multiple research meetings and a return to the literature prompted the re-presentation ${ }^{28}$ of data according to Wenger's social model of learning, which guided the study.

Table 1. Coding Procedures Used in a Study in Which High-Performing Doctor of Pharmacy Students Were Interviewed to Identify Study Behaviors Associated with Academic Success in an Active-Learning Curriculum

\begin{tabular}{|c|c|c|c|}
\hline Codes & Themes & $\begin{array}{c}\text { Wenger's } \\
\text { Framework Arm }\end{array}$ & $\begin{array}{l}\text { Representation of } \\
\text { Framework Arm }\end{array}$ \\
\hline $\begin{array}{l}\text { Doing pre-work } \\
\text { Listening to lectures } \\
\text { Looking at slides } \\
\text { Putting in the time } \\
\text { Going to class } \\
\text { Organizing } \\
\text { Preparing }\end{array}$ & $\begin{array}{l}\text { Preparing for class Preparing } \\
\text { for testing }\end{array}$ & Practice & Learning as doing \\
\hline $\begin{array}{l}\text { Asking other students } \\
\text { Asking professors } \\
\text { Talking through problems } \\
\text { Learning while teaching }\end{array}$ & Seeking help & Community & Learning as belonging \\
\hline $\begin{array}{l}\text { Knowing what works } \\
\text { Focusing on needs } \\
\text { Developing study techniques } \\
\text { Minimizing distractions } \\
\text { Studying at home }\end{array}$ & Knowing oneself & Identity & Learning as becoming \\
\hline $\begin{array}{l}\text { Using past experiences } \\
\text { Evaluating performance } \\
\text { Learning how to learn }\end{array}$ & Building on strengths & Meaning & Learning as experience \\
\hline
\end{tabular}




\section{American Journal of Pharmaceutical Education 2020; 84 (7) Article 7695.}

\section{RESULTS}

Thirteen pharmacy students comprised the sample for this study because the research team agreed that after 13 interviews, the point of saturation, where no new insights or understanding were being revealed, had been reached. ${ }^{27}$ The average age of the students was 25 years (range, 20 to 31 years). Student demographics and their undergraduate degrees are noted in Table 2. We did not find any significant differences between the responses of male and female participants, second- and third-year students, students from different campus location, students who had obtained different undergraduate degrees, or students with and without prior experience with activelearning models as explored through multiple data matrices. The thematic analysis suggested that the students engaged in five primary behaviors that they believed were responsible for their academic success. These were labeled as themes: preparing for class, preparing for testing, seeking help, knowing myself, and building on strengths. These themes were mapped to the four arms of Wenger's framework $^{21,22}$ as described in Table 1. Corresponding quotes are listed in Appendix 2.

The first two themes, preparing for class and preparing for testing, were mapped to the Wenger's framework arm of practice and represented as learning as doing. High-performing students in this study described a plethora of ways in which they engaged with the material provided by faculty and generated by the learning community to prepare for classes and tests in an activelearning environment.

Students indicated that they engaged in multiple methods of preparing for class (Table 3 ). The methods

Table 2. Demographics of Participants in a Study in Which High-Performing Doctor of Pharmacy Students Were Interviewed to Identify Study Behaviors Associated With Academic Success in an Active-Learning Curriculum $(\mathrm{n}=13)$

\begin{tabular}{ll}
\hline Variable & n (\%) \\
\hline Female & $8(62)$ \\
PY3 & $8(62)$ \\
PY4 & $5(38)$ \\
Main campus & $7(54)$ \\
Branch campus & $6(46)$ \\
Prior pharmacy (work) experience & $9(69)$ \\
Prior active learning (undergrad) experience & $2(15)$ \\
Undergraduate degrees & \\
Biology & $5(38)$ \\
Medical/Pharmacy Science & $3(23)$ \\
Other & $3(23)$ \\
Biochemistry/Chemistry & $2(15)$ \\
\hline Abbian
\end{tabular}

Abbreviations: PY3=student pharmacist in the third professional year, PY4=student pharmacist in the fourth professional year they used for preparing for class changed depending on the type of class (Appendix 2, Quote 1). Within the theme preparing for class, we captured a multitude of ways in which students engaged with material prior to class. The majority of participants $(n=12,92 \%)$ prepared for class by engaging with the pre-class work they had been assigned. Only one participant $(n=1,8 \%)$ reported that the first time they engaged with the material was in class (Appendix 2, Quote 2). Most of the students always went to class ( $\mathrm{n}=11,85 \%)$ (Appendix 2, Quote 3), revealing a potential difference between the Rho Chi students and their peers (Appendix 2, Quote 4). Students explained that going to class provided an opportunity to clarify information and ask questions about material they did not understand. Two students (15\%) confessed to not always attending classes that were not mandatory. One student had an immunity-reducing health condition and the other explained deciding whether to attend class depended on the course and professor (Appendix 2, Quote 5).

The ways the majority of students $(n=7,54 \%)$ prepared for tests were very similar regardless of the type of test or course. Of those whose test preparation habits were different, the distinction was in the amount of time spent preparing, depending on the amount or volume of material, and in whether they preferred to prepare for a test in a group or alone. Students employed a variety of techniques while preparing for a test. They organized by maintaining folders of information, creating calendars, and using colors to help prioritize tasks. They prepared by doing pre-work, watching videos, creating study guides, and reviewing PowerPoint slides. Students talked about the importance of being exposed to the material by "touching

Table 3. Methods of Preparing for Class Reported by HighPerforming Doctor of Pharmacy Students Interviewed to Identify Study Behaviors Associated With Academic Success

\begin{tabular}{lr}
\hline Method & No. (\%) \\
\hline Re-watch online video lecture & $10(77)$ \\
Answer learning objectives & $10(77)$ \\
Handwrite/highlight notes & $10(77)$ \\
Create personal study guide & $10(77)$ \\
Review in-class materials & $9(69)$ \\
Teach the material to another & $9(69)$ \\
Meet with study group & $8(62)$ \\
Type up notes & $7(54)$ \\
Make charts/tables & $6(46)$ \\
Utilize YouTube or other online resource & $6(46)$ \\
Write your personal quiz questions & $4(31)$ \\
Ask questions over social media & $3(23)$ \\
Make flashcards & $2(15)$ \\
Create concept maps & $1(8)$ \\
\hline
\end{tabular}




\section{American Journal of Pharmaceutical Education 2020; 84 (7) Article 7695.}

something every day" and simply "putting in the time." Sometimes this was achieved through problem-solving, memorizing, or creating mnemonics. They tested their knowledge by taking online tests provided by faculty members, developing questions of their own, or quizzing each other in small groups. When they needed clarification about something, they asked a peer or a faculty member.

The third theme, seeking help, was mapped to the Wenger's framework arm community and represented as learning as belonging. The community in which we learn is where participation is recognized as competence in the social learning theory. Not surprisingly, students described Wenger's sense of belonging in their attempts to seek help and clarify concepts as needed. ${ }^{21,22}$ First and most commonly, students collaborated with their peers and found value in studying strategically in groups (Appendix 2, quotes 6 and 7). When students did not find the answers they were looking for from peers, they sought help from instructors (Appendix 2, Quotes 8 through 11).

The idea of group belonging also emerged in response to the importance placed on group work. Approximately half of the students $(n=6,46 \%)$ regularly worked in groups (Appendix 2, quotes 12 and 13). Students used the group strategy when they expected a particular subject or topic to be challenging. The other half of students $(n=7,54 \%)$ did not work in groups (Appendix 2, quotes 14 and 15). Some students bounced back and forth, using groups only when they believed that approach would be most beneficial.

Wenger describes the learner's identity as being a central element to the theory. ${ }^{21,22}$ Identification involves modulation as a person identifies more or less with the community and defines the need to belong or disidentify alongside the need to be accountable for its success. ${ }^{29}$ The fourth theme, knowing oneself, was mapped to Wenger's framework arm Identity, and represented as learning as becoming. The high-performing students in this study demonstrated this element as they described heightened awareness of their own habits and preferences, noting each one's ability to help or hinder the capacity for success. When the students' natural tendencies pulled them away from studying, they acted in such a way as to minimize the impact of these disruptions. This was exemplified in student responses to the query about where they studied best. Seven students (54\%) reported studying at home, four (31\%) at school, and three (23\%) "anywhere it was quiet." These decisions were reportedly made based on an awareness of the environment and where distractions could be minimized. Some were more easily distracted at school (Appendix 2, quotes, 16 and 17) while others were more easily distracted at home (Appendix 2, quote 18).

We also asked students when they preferred to study and received similar responses. Students reported studying in the morning, afternoon, late into the evening, and on weekends. One student told us that he studied whenever he had a block of time available. The highperforming students were experts at managing distractions, acknowledging that doing so was difficult. In order to manage interruptions by social media or text messages, students employed a variety of techniques. These included deciding what was important at that moment and whether to make time for it, closing extraneous tabs on computer screens, putting smart phones away, and using these distractions as a reward or an opportunity to take a break (Appendix 2, quotes 19, 20, and 21).

The fifth theme, building on strengths, was mapped to Wenger's framework arm, meaning, and represented as learning as experience. Students were asked to reflect on the differences between undergraduate education and graduate pharmacy education. Eight students $(62 \%)$ said that pharmacy school was easier than undergraduate education (Appendix 2, quote 22) and five students (38\%) said that pharmacy school was harder (Appendix 2, 23). These academically high-performing students used their previous and current pharmacy work experiences to help them with recall during classwork and studying (Appendix 2 , quote 24). However, none of the students placed a large emphasis on these experiences in terms of their academic success in pharmacy school (Appendix 2, quote 25).

The students had a great deal to say about how the active-learning model influenced their experience of studying in pharmacy school (Appendix 2, quotes 26 through 28). Most students stated that active learning was actually harder but that it created opportunities for practical application of knowledge as they learned it.

In summary, our interviews with the academically highperforming students indicated the participants had built on their own strengths (experience/meaning) and engaged in behaviors that maximized their success (doing/practice) and minimized their weaknesses. They knew what worked for them (belonging/community) and capitalized on that knowledge, seeking help when it was needed (becoming/identity).

\section{DISCUSSION}

The purpose of this study was to explore specific study behaviors that promoted student pharmacist success in an active-learning classroom setting. At first glance, the ways in which academically successful students prepared and studied for classes are not surprising. For the most part, students completed pre-class work, attended class, engaged by participating in in-class activities and discussions, and put in additional time and effort after class to reinforce learned knowledge and/or skills. Although these students used a variety of methods for class preparation and had varied attitudes toward class 


\section{American Journal of Pharmaceutical Education 2020; 84 (7) Article 7695.}

attendance, the majority reported doing all the assigned pre-work and attending class regularly. In-class time was mainly used to engage with faculty members in clarifying concepts and expectations.

Students in the WSU CPPS curriculum are exposed to several different types of testing, depending on the format of the course. Aside from the amount of time they spent studying, most of the high-performing students utilized consistent methods to prepare for testing in the different types of WSU CPPS courses. The specific behaviors employed by individual students, however, varied and included highly effective methods. This is consistent with the findings of Dunlosky and colleagues, ${ }^{7}$ who advocate organization, preparation, repeated exposure to content, self-testing, and seeking help. In addition to using proven learning behaviors, the high-performing students in our study showed an ability to discern which study behaviors were best to use for specific courses and for different assessments within a given course. Future research could further examine how high-performing students develop superior metacognition.

To realize the full benefits of a flipped classroom, faculty members must effectively align learning objectives and content, providing engaging learning activities, and students must attend class and actively participate. While the majority of high-performing students reported attending class, some placed a greater emphasis on reviewing pre-class materials over engaging with content and peers in class. Thus, a potential disadvantage of self-regulation in active learning classrooms is the adoption of undesirable attendance strategies by students who perceive a lack of value in classroom activities. Research devoted to boosting attendance rates in active-learning communities is needed.

The specific strategies used by individual students to study and be successful vary according to different factors, including individual learning styles and preferences, prior experiences, the type of course, and the type of assessment model. What was universal among this cohort was a commitment to adequate preparation prior to assessments, an awareness of the specific study strategies that are effective, and a willingness to seek out help when needed. These findings are consistent with the concepts of self-regulated learning and the significant impact of effective metacognition on academic performance. ${ }^{1,3}$

Faculty members can use the results of this study in designing orientation and student success programs to better prepare incoming students for a smooth transition into the curriculum and to support and provide resources for those who are struggling. Investigators believed that a list of proven study behaviors might be compiled and shared with incoming students as part of their orientation to promote success in the curriculum. Instead, the investigators found that successful students employ a variety of study tools, techniques, and behaviors as they prepare for class and for tests. From these students, we have learned that academic success may be less dependent on specific behaviors and more related to an ability to self-regulate learning through metacognition. This was noted in descriptions of help-seeking, time management, and willingness to vary learning strategies according to the demands of a particular course or assessment. The emphasis placed on metacognitive strategies is consistent with the foundational work of Zimmerman and Pintrich that describes self-regulated learning. ${ }^{1,2,4}$

One limitation of this study was the singular focus on the academic performance of the students included in the study. The CPPS faculty know that student pharmacists choose to set themselves apart as high performers through activities beyond academics, such as involvement in student organizations, participation on college or university committees, volunteering, and participation in internships. While academic performance is an important aspect of being a student pharmacist, it does not necessarily constitute the only opportunity for students to demonstrate success. However, this study was not designed to explore alternate definitions of success.

Another limitation of this study was the issue of representativeness. The 13 student pharmacists included in this study may not have accurately represented the entire Rho Chi membership of high-performing students. Although saturation was reached, a comprehensive interview of all Rho Chi members may have revealed outliers that would have led to further exploration.

Third, this study design reflected the need for an initial exploration because little was known about the study habits of high-performing students in an active-learning environment such as ours. ${ }^{26}$ To gain a deeper understanding of the differences between high-performers and low-performers or between students in a traditional classroom and an active-learning classroom, a study design that included comparison groups would have been required.

Finally, the investigators implemented measures to mitigate the impact of implicit and explicit bias. This includes an acknowledgment that the sample used in our study may have simply been one of high-performing students who would have achieved academic success regardless of their learning environment. Miles and colleagues describe 13 tactics for testing and confirming findings that help to avoid analytic bias that would weaken or invalidate findings. ${ }^{27}$ Specific measures employed by the investigators included checking for researcher effects by having a non-CPPS faculty member interview the students and perform first-level coding, checking the meaning of outliers using extreme cases, as in the issue of going to class or not going to class, 


\section{American Journal of Pharmaceutical Education 2020; 84 (7) Article 7695.}

and looking for negative evidence by counting cases and creating data matrices. As a result, we believe the findings are objective and confirmable because we described our procedures explicitly; dependable and valid because we fully documented study methods, which were performed with reasonable care; and transferable because we provided detailed descriptions of study sample and setting. This research could be used by other pharmacy schools to identify behaviors that promote student success in an active-learning community.

\section{CONCLUSION}

Academically high-performing students employ a wide variety of learning and study behaviors that contribute to their academic success. Through interviews of pharmacy students with the strongest academic performance in an active-learning pharmacy curriculum, we identified behaviors that allowed these students to thrive and situated these behaviors within the social learning framework to maximize transferability. Future research comparing the effectiveness of these behaviors in traditional vs active-learning classrooms could help to identify behaviors that are critical to higher-ordered learning. Similarly, confirming these findings in a study designed to compare learners with the highest and lowest academic standing may reveal behaviors critical to academic success. These observations have implications for advisors, faculty members, and others who are charged with orienting and preparing incoming students for matriculation into professional programs that employ active learning and could ultimately provide the foundation for a guide to facilitate the academic success of future students.

\section{REFERENCES}

1. Zimmerman BJ. Self-regulated learning and academic achievement: an overview. Educ Psychol. 1990;25(1):3-17. 2. Zimmerman B. Attaining self-regulation: a social cognitive perspective. In: Boekaerts M, Pintrich PR, Zeidner M, eds. Handbook of Self-Regulation. Burlington, MA: Elsevier Academic Press; 2005. 3. Colthorpe K, Ogiji J, Ainscough L, Zimbardi K, Anderson S. Effect of metacognitive prompts on undergraduate pharmacy students' self-regulated learning behavior. Am J Pharm Educ. 2019;83(4):Article 6646.

4. Pintrich PR, De Groot EV. Motivational and self-regulated learning components of classroom academic performance. $J E d u c$ Psychol. 1990;82(1):33.

5. Schneider EF, Castleberry AN, Vuk J, Stowe CD. Pharmacy students' ability to think about thinking. Am J Pharm Educ. 2014;78(8):Article 148.

6. Payakachat N, Gubbins PO, Ragland D, et al. Academic helpseeking behavior among student pharmacists. Am J Pharm Educ. 2013;77(1):Article 7.

7. Dunlosky J, Rawson KA, Marsh EJ, Nathan MJ, Willingham DT. Improving students' learning with effective learning techniques: Promising directions from cognitive and educational psychology. Psychol Sci Public Interest. 2013;14(1):4-58.
8. West C, Sadoski M. Do study strategies predict academic performance in medical school? Med Educ. 2011;45(7):696-703. 9. Salamonson Y, Everett B, Koch J, Wilson I, Davidson PM. Learning strategies of first year nursing and medical students: A comparative study. Int J Nurs Stud. 2009;46(12):1541-1547.

10. Sansgiry SS, Bhosle M, Sail K. Factors that affect academic performance among pharmacy students. Am J Pharm Educ. 2006;70(5):Article 104.

11. Brown D. An evidence-based analysis of learning practices: the need for pharmacy students to employ more effective study strategies. Curr Pharm Teach Learn. 2017;9(2):163-170.

12. Persky AM. A four year longitudinal study of student learning strategies. Curr Pharm Teach Learn. 2018;10(11):1496-1500.

13. Persky AM, Hudson SL. A snapshot of student study strategies across a professional pharmacy curriculum: are students using evidence-based practice? Curr Pharm Teach Learn.

2016;8(2):141-147.

14. Boevé AJ, Meijer RR, Bosker RJ, Vugteveen J, Hoekstra R, Albers CJ. Implementing the flipped classroom: an exploration of study behaviour and student performance. High Educ.

2017;74(6):1015-1032.

15. Camiel LD, Mistry A, Schnee D, et al. Students' attitudes, academic performance and preferences for content delivery in a very large self-care course redesign. Am J Pharm Educ. 2016;80(4):Article 67.

16. Bray BS, Remsberg CM, Robinson JD, et al. Implementation and preliminary evaluation of an honours-satisfactory-fail competencybased assessment model in a doctor of pharmacy programme. Pharm Educ. 2017;17(1):143-153.

17. Remsberg CM, Bray BS, Wright SK, et al. Design, implementation, and assessment approaches within a pharmacogenomics course. Am J Pharm Educ. 2017;81(1):Article 11. 18. Margolis AR, Porter AL, Pitterle ME. Best practices for use of blended learning. Am J Pharm Educ. 2017;81(3):Article 49.

19. Howard M, Persky AM. Helpful tips for new users of active learning. Am J Pharm Educ. 2015;79(4):Article 46.

20. Persky AM, McLaughlin JE. The flipped classroom - from theory to practice in health professional education. Am J Pharm Educ. 2017;81(6):Article 118.

21. Wenger E. Communities of Practice: Learning, Meaning and Identity. Cambridge: Cambridge University Press; 1998.

22. Wenger E. A social theory of learning. In: Illeris K, ed. Contemporary Theories of Learning: Learning Theorists ... In Their Own Words. London: Routledge; 2009.

23. Sandelowski M. Combining qualitative and quantitative sampling, data collection, and analysis techniques in mixed-method studies. Res Nurs Health. 2000;23(3):246-255.

24. Sandelowski M. What's in a name? Qualitative description revisited. Res Nurs Health. 2010;33(1):77-84.

25. Colorafi K, Evans B. Qualitative descriptive methods in health science research. HERD. 2016;9(4):16-25.

26. Crewsell J. Qualitative Inquiry and Research Design. 3rd ed. Thousand Oaks, CA: Sage Publications; 2013.

27. Miles MB, Huberman AM, Saldaña J. Qualitative Data Analysis: A Methods Sourcebook. Third ed. Thousand Oaks, CA: Sage Publications, Inc; 2014.

28. Sandelowski M. Writing a good read: Strategies for re-presenting qualitative data. Res Nurs Health. 1998;21(4):375-382.

29. Graven M, Lerman S. Book Review. Wenger E. (1998). Communities of practice: Learning, meaning and identity. J Math Teach Ed. 2003;6(2):185-194. 


\section{American Journal of Pharmaceutical Education 2020; 84 (7) Article 7695.}

\section{Appendix 1. Interview Questions}

\section{Demographic Questions:}

What is your age?

What is your gender?

What is your anticipated year of graduation from the College of Pharmacy?

What is your undergraduate degree?

What previous experience with active learning or flipped classrooms did you have prior to starting pharmacy school?

What previous experience in pharmacy did you have prior to starting pharmacy school (pharmacy assistant, technician, other?) Are you currently working as a pharmacy intern? If yes, how many hours per week are you working?

\section{Interview questions:}

Tell me about how you study. Walk me through your study habits during the average week.

Prompts, as needed:

I'm going to read a list of study habits that have been reported by our students. Can you talk about the ways in which you do these things when you are preparing for an exam?

Re-watch online video lectures

Answer learning objectives

Review in-class materials (cases, practice problems, Kahoot questions, etc.)

Type up notes

Handwrite, highlight notes

Meet with a study group

Make flashcards

Make charts or tables

Create your own study guide

Create concept maps (i.e. flow chart showing how concepts related to each other)

Write your own quiz questions

Teach the material to another person

Ask questions over social media (Facebook, etc.)

Utilize YouTube or other online resources

Anything we missed?

When do you study best? Can you tell me why that is?

Where do you like to study? Can you tell me why that is?

Does your study method differ by class? How do you prioritize? Give me examples of the ways you like to study for a couple of your different classes.

Tell me what you think about studying in groups. Do you prefer to work with others, study by yourself, or a combination? Does that vary by class? Do you typically study with the same people or do you mix it up?

How do you study to prepare to come to class?

How do you study to prepare for the block tests? Is that different than preparations for non-block tests?

Tell me about how you study or review after an assessment.

How do you handle distractions like social media, email, television, etc.?

How do you engage with your faculty/instructors to help with studying? If you do not understand a concept, how do you go about getting clarification?

How are your study habits different in pharmacy school than they were in undergrad? How are they different with active learning vs traditional lectures?

How do you use your past and/or current pharmacy experiences to help you study?

Do you have any additional comments that you would like to share? Any information that you think would be helpful in our study? 
American Journal of Pharmaceutical Education 2020; 84 (7) Article 7695.

Appendix 2. High-Performing Doctor of Pharmacy Students Interview Respondent Quotes Organized by Theme

\begin{tabular}{|c|c|}
\hline Theme & Corresponding Student Quotes \\
\hline Preparing for class & $\begin{array}{l}\text { 1. "Kinetics is math and you have to practice problems. Pharmacology is rote memory. We just } \\
\text { have to memorize." } \\
\text { 2. "[I] download everything ahead of time but I don't really walk through it much ... maybe just a } \\
\text { glance at the power point. Then basically I use class time as my introduction to the material." } \\
\text { 3. "I always go to every single class." } \\
\text { 4. "Only a third of my class ever shows up to class. So, you are able to almost have a private school } \\
\text { experience." }\end{array}$ \\
\hline Preparing for testing & $\begin{array}{l}\text { 5. "Some professors, they put in-class activities on tests. If I know that professor is going to be } \\
\text { lecturing, I would go to class that day. But I don't know, you learn patterns with different } \\
\text { professors, and you can decide whether you should go to class or not. Well, sometimes it's } \\
\text { really not that helpful to go to class." }\end{array}$ \\
\hline Seeking help & $\begin{array}{l}\text { 6. "We may have interpreted some material a little differently, so it really helps to have different } \\
\text { perspectives" } \\
\text { 7. "I think that studying in groups is beneficial because if someone doesn't quite understand the } \\
\text { concept then you can usually bounce the idea off other people. And nine times out of ten } \\
\text { everyone might not know everything, but they're going to know that certain concept or maybe } \\
\text { hear what the professor said in that certain situation. And so it ends up being that as a group you } \\
\text { get the collective information you need to know." } \\
\text { 8. "In class would be my first resort." } \\
\text { 9. "I probably asked five or ten questions per class." } \\
\text { 10. "If I have a quick question, I email [the instructor]" } \\
\text { 11. "I would just go to their office hours. . and discuss what I missed." } \\
\text { 12. "I think [group studying] incredibly helpful" } \\
\text { 13. "I learn best when I'm teaching others." } \\
\text { 14. "I hate it" because, "I felt like maybe time was wasted or wrong information was spread and that } \\
\text { would frustrate me." Another said that working in groups was not beneficial because } \\
\text { 15. "I don't always know the answer right away ... and I need to figure it out on my own. If I don't } \\
\text { do the work and someone goes 'oh, it's here, [this] is how you do it,' that's not going to help } \\
\text { me." }\end{array}$ \\
\hline Knowing oneself & $\begin{array}{l}\text { 16. "It's too distracting at school" } \\
\text { 17. "I like to study someplace quiet, so home is the best." } \\
\text { 18. "I fall asleep at home if I try to study there or get distracted." } \\
\text { 19. "What we'll do, we'll put on headphones and sit next to each other. . and we'll say, 'For the next } \\
45 \text { minutes, you are not allowed to check social media - only study. If I catch you doing } \\
\text { something else, I'm going to slap you."” } \\
\text { 20. "The way I see things is that you just have to get in the zone, so I always make my study guides } \\
\text { on Microsoft Word. There's a little button at the bottom that says focus. [It expands] your whole } \\
\text { entire study guide and it blocks out [everything else]." } \\
\text { 21. "I'll do one run through and I'll get a reward, or I go for a walk or a run or something like that. } \\
\text { Or I watch a simple short video, or whatever, just to distract myself for } 20 \text { minutes and then go } \\
\text { do another run-through." }\end{array}$ \\
\hline
\end{tabular}

(Continued) 
American Journal of Pharmaceutical Education 2020; 84 (7) Article 7695.

(Continued)

\begin{tabular}{l} 
Corresponding Student Quotes \\
\hline Building on strengths \\
22. "Pharmacy school is too easy. If the class complained a lot [about a test question], they'd just \\
drop the question. That never happened [in undergrad]." \\
23. "In undergrad I did not need to study as much." \\
24. "I don't think it drastically influenced the way I did in most of my classes. Some classes, it \\
makes a big difference, where just knowing more memorization of drugs [was essential to \\
success]. That really helped, because you'd think of a patient and what they were taking, and it's \\
a story instead of just a [drug] name." \\
25. "I think I was ahead of my peers when we had to memorize brands and generics, and especially \\
the top 200 [drugs]. But after the first semester, not really." \\
26. "You have access to more material, with the pre-recorded videos and stuff, which I love. You \\
get access to more material. I like that." \\
27. "I think that active learning is a great way to learn. Especially for a graduate program. We're all \\
adults now, and I think with that there needs to be an expectation that you need to be a self- \\
motivated learner. Active learning lets you prioritize and see how to schedule things. Active \\
learning is geared towards people who will take the time." \\
28. "One benefit of the active learning model is that it gives the student the chance to learn in many \\
different ways. So I'm not an auditory learner, but we have the active in-class [activities] which \\
helps with all the other styles of learning. . I like this model because it gives everyone a better \\
chance of learning the material, plus you're forced into multiple exposures which is really nice." \\
29. "[We] create this nice chart, or table to go over this class of drugs. Let's put all these opioids in \\
the table and get their adverse effects and their interactions and stuff like that... where it actually \\
provides practical use to you for studying. I feel like that is helpful. I feel like most of the \\
professors had the pragmatic and practice [approach]."
\end{tabular}

